\title{
A Comparative Study of Examination Techniques for Imaging Avian Eggshell.
}

Sandra L. Westmoreland. The Department of Biology and The Center for Electron Microscopy, The University of Texas at Arlington, Arlington, Texas 76019.

The avian eggshell is an excellent subject for the study of biomineralization. The organic matrix and calcium carbonate crystals are deposited quickly in the hen's oviduct and in abundant quantity. Five grams of calcium carbonate shell is fabricated in less than 20 hours [1]. Examination of the eggshell has previously been conducted using various forms of microscopy in an effort to understand the structure and function of various shell features [2,3]. Imaging avian eggshell is a difficult task, however. Because it is a complex biomaterial, no one preparation technique or method of microscopy can present a complete picture. Investigators obtain different perspectives of eggshell based on the method of examination. Only by combining information obtained using various techniques can the true picture immerge. The avian eggshell, as represented by the shell of the White Leghorn chicken, is composed of calcium carbonate crystals interspersed with a protein matrix. The external shell surface is covered with an organic cuticle, while the shell interior is lined with organic shell membranes. Shell structures support shell functions: physical protection of the embryo and provision of a source of calcium for the growing embryo. Microscopic pores penetrate the shell allowing for gas exchange with the egg interior without allowing desiccation or microbe invasion.

By using various physical and chemical treatments in conjunction with light, scanning electron and transmission electron microscopy, various shell components have been exposed and examined in this long-term study for better understanding. Scanning electron microscopy of untreated shell provided a basis for comparison to treatment methods (FIG 1). Ground sections of epoxy-embedded eggshell were viewed with light microscopy. These sections allowed a view of the shell interior including the calcium reserve assembly, the site from which calcium is removed during embryogenesis. Microtomed sections of embedded shell were viewed with both light microscopy and transmission electron microscopy (FIG 2). These sections provided information about the structure of shell membranes and the interrelationship of shell crystals and shell matrix. Changes in the crystalline structure of the eggshell were effected using buffered solutions of $\mathrm{pH}$ 6.6-7.6, revealing the protein matrix for imaging with the scanning electron microscope. Eggshell was also treated with a baffle furnace at 700 degrees Celsius, exposing the crystalline structure. Polishing and chemical treatments were used to remove the shell's cuticle, uncovering "pore plugs" in the mouths of shell pores. High-pressure epoxy-embedded eggshell was used to prepare casts of shell pores and interior shell surfaces for imaging with scanning electron microscopy (FIG 3). The comparison of micrographs obtained using various forms of microscopy and preparation techniques has confirmed the structure of avian eggshell while adding significant new data to expand its understanding.

\section{References}

[1] J.L. Arias, et al., International Review of Cytology. 145 (1993) 217.

[2] J.E. Dennis, et al., Journal of Morphology. 228 (1996) 287.

[3] J.W. Dieckert, et al., Poultry Science. 1569 (1989) 1569.

[4] The aid provided by Dr. Howard Arnott is gratefully acknowledged. 


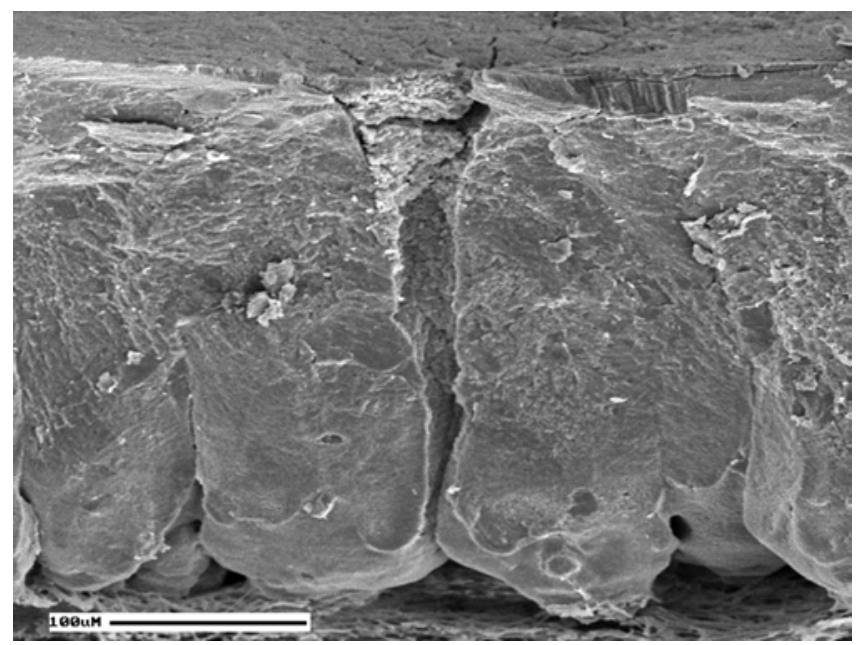

FIG. 1. Radial section of eggshell (SEM).

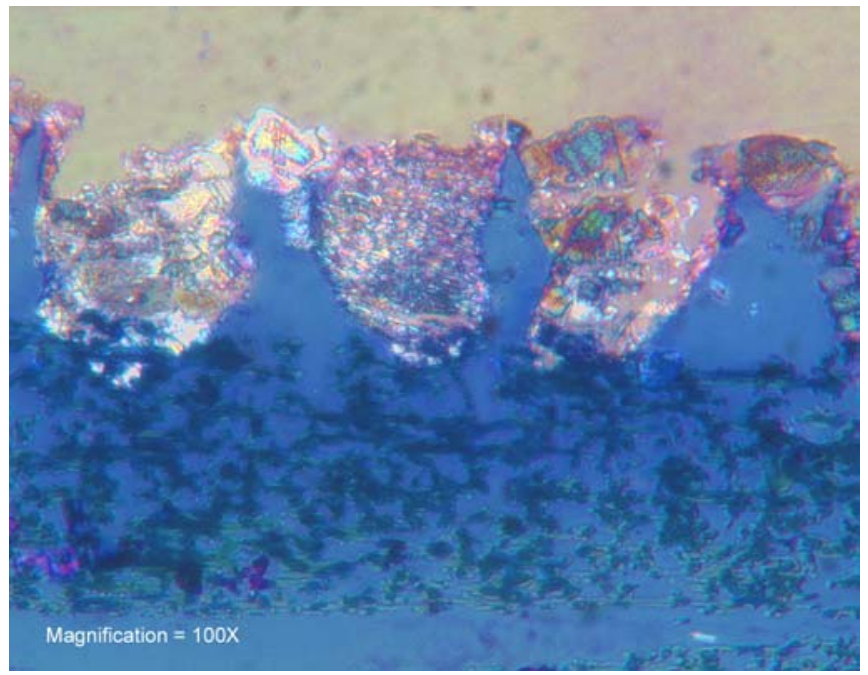

FIG.2. Microtomed section of embedded eggshell (LM).

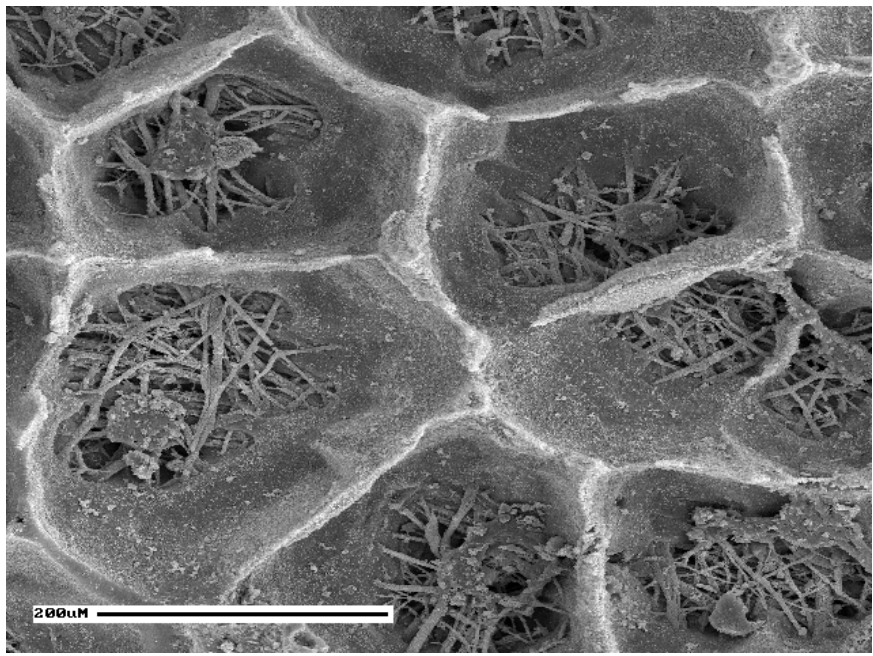

FIG. 3. Plastic cast of eggshell mammillary cones. 